\title{
Por uma sociologia relacional do campo jurídico brasileiro
}

\section{In a defense of a relational sociology of brazilian legal field}

Felipe Araújo Castro ${ }^{1}$

Resumo: Tendo por referência o marco teórico da sociologia relacional, como desenvolvida especialmente por Bourdieu, nosso objetivo é descrever o campo jurídico brasileiro como um espaço social relativamente autônomo, no qual estão inseridas as práticas dos sujeitos habilitados à ação dentro dos seus limites (os agentes jurídicos). Nossa hipótese é que a práxis desses agentes jurídicos é melhor compreendida a partir de observações empíricas tratadas por meio das mediações das categorias campo e habitus. Para demonstrar as vantagens dessa abordagem, apresentaremos o estado da arte sobre tais categorias, mas atentos ao desenvolvimento específico do campo jurídico nacional, enfatizando os contextos sócio-históricos nos quais emerge e se relaciona.

Palavras-chave: sociologia relacional; campo e habitus; campo jurídico brasileiro;

Abstract: Based on the theoretical framework from

1 Doutor em Direito pela UFMG. Graduado e Mestre em Direito Constitucional pela UFRN. Professor de História do Direito na Universidade Federal Rural do Semi-Árido. 
relational sociology as developed especially by Bourdieu, our objective is to describe the Brazilian legal field as a relatively autonomous social space in which are inserted the practices of the subjects allowed to act within their limits (legal agents). Our main hypothesis is that the praxis of these legal agents is best understood from empirical observations dealt with through the mediations of Bourdieu's most relevant categories: field and habitus. To demonstrate the advantages of this approach, we will present the state of art on such categories, but attentive to the specific development of the national legal field, emphasizing the socio-historical contexts in which it emerges and is related.

Keywords: relational sociology; field and habitus. Brazilian legal field.

\section{Introdução}

Para compreender razoavelmente, ainda que sempre provisoriamente, como os indivíduos pensam e se comportam em sociedade é imprescindível ter como ponto de partida a noção de que sujeitos não são "espíritos espontâneos", no sentido de que não são isolados e completamente livres. Antes, homens e mulheres são produtos de uma história individual específica sobre a qual infere uma série de vetores associados aos distintos espaços de socialização frequentados pelos indivíduos durante suas respectivas trajetórias. Não obstante, os sujeitos também são, além de frutos de suas trajetórias individuais, resultados de uma dada história coletiva que a estes se impõe por meio das relações estabelecidas nesses espaços de socialização estruturantes e previamente estruturados.

Na soma, homens e mulheres são resultados do encontro desses dois estados sociais distintos e complementares, a história objetivada sob a forma das estruturas e dos 
mecanismos presentes nos espaços sociais (nos campos) e a história incorporada em seus corpos por meio do habitus, que fornece uma cumplicidade entre agentes e funda uma relação dialética entre essas duas histórias. ${ }^{2}$ Esses agentes relacionam-se entre si, dentro dos espaços sociais nos quais estão habilitados a atuar, buscando a imposição uns aos outros dos princípios de visão e divisão social que possuem, portanto, disputam para exercerem a dominação simbólica no campo.

A sociologia relacional ${ }^{3}$ propõe que apenas seja possível compreender as dinâmicas específicas das instituiçõos e dos indivíduos, isoladamente considerados e organizados em grupos, caso seja levado em consideração a análise dialética entre os agentes e as estruturas. Portanto, a proposta praxilógica endossa a crítica das correntes sociológicas objetivistas contra a insuficiência do conhecimento social advindo das "experiências primeiras" (subjetivistas), porém, indica que o movimento de superação dessas perspectivas não se encerra nessa crítica. A análise deve retornar a essas experiências subjetivas, uma vez que elas influenciam a construção e aplicação dos modelos objetivos do mundo social que, por sua vez, modificam as experiências primeiras. ${ }^{4}$ Dessa perspectiva, é essa relação dialética "a protagonista da ação sobre o mundo social" ${ }^{5}$

2 BOURDIEU, 2001. p. 184.

3 Ainda que saibamos que Bourdieu não seja o único a realizar uma sociologia relacional, em função da ênfase e da ressignificação que o autor deu a essa perspectiva, tendo fundado um campo de investigações sócio-empíricas extremamente frutífero, utilizaremos os termos sociologia relacional e sociologia bourdieusiana indistintamente para fazer menção a nosso marco teórico, a exemplo de PAPILLOUD \& SCHULTZE, 2018. A originalidade de abordagem bourdieusiana e algumas contribuições contemporâneas do campo de sua sociologia relacional estão documentados em WACQUANT, 2013.

4 TARGA, 2017, p. 24.

5 TARGA, 2017, p. 22. 
Dessa forma, as categorias de pensamento, as categorias de juízo, os sistemas de percepção e os sistemas de valores são igualmente produtos desses complexos processos de interação social:

O inconsciente é a história - a história coletiva que produziu nossas categorias de pensamento, e a história individual por meio da qual elas nos foram inculcadas: por exemplo, é a história social das instituições de ensino e a história de nossa relação singular com essas instituições que podem nos oferecer algumas verdadeiras revelações sobre as estruturas objetivas e subjetivas que, a despeito de nossa vontade, sempre orientam nosso pensamento. ${ }^{6}$

Durante a sua obra, Pierre Bourdieu buscou resgatar e reinterpretar as noções de habitus e campo, a partir da tradição do pensamento filosófico, apresentando-as sempre como instrumentos conceituais complementares; seu objetivo foi desenvolver uma estratégia para desvelar o inconsciente naturalizado das relações sociais. Essa naturalização se manifesta notadamente nas noções enganosas do homem completamente livre das teorias do agir racional. Ao realizar essa crítica, procurou concomitantemente e conscientemente evitar cair em explicações deterministas da ação, que tendiam a eliminação do vetor vontade das considerações sobre o agir humano.

Seu conceito de habitus - uma visão de mundo compartilhada por indivíduos com características sociais comuns, produzida pela ação de mecanismos como a educação formal e familiar, ritos de passagem e práticas de sociabilidade que incutem nos indivíduos as estruturas objetivas de poder no campo e na sociedade e que definem suas próprias posições (e posturas, práticas, gestual etc.) nesse campo -, associado ao conceito de campo - um espaço social de estruturas e agentes com características comuns e que disputam um tipo de capital próprio desse espaço, como o capital político ou o capital jurídico -, fornece uma importante teoria da ação e, ao mesmo tempo, uma interessante "solução" para o aparente

6 BOURDIEU, 2001, p. 19. 
dilema ação vs. estrutura na teoria social. ${ }^{7}$

Nesse processo, buscou dar a essas categorias - campo e habitus - novas significações que foram tomando forma a partir das necessidades de suas pesquisas empíricas, como etnólogo e sociólogo, bem como em embates teóricos acerca da lógica da prática. Aliás, a noção da dialética complementar entre teoria e prática, entendendo a última como momento preponderante da pesquisa científica, constituiu o cerne do método de investigação e exposição do autor.

Nosso objetivo é demonstrar que o espaço social relativamente autônomo constituído pelo campo jurídico brasileiro, no qual estão inseridas as práticas dos sujeitos habilitados à ação dentro dos seus limites, é melhor compreendido a partir de observações empíricas tratadas por meio das mediações das categorias campo e habitus. Diante desse cenário, pretendemos apresentar o estado da arte de tais categorias aplicadas ao contexto do campo jurídico nacional, como forma de contribuir para a produção acadêmica na área.

Debruçar-nos-emos primeiramente sobre a noção de habitus, por entender que tenha sido esse o caminho desenvolvido por Bourdieu como consequência quase lógica de suas investigações. Com efeito, na medida em que desenvolvia a dimensão das práticas individuais, filtradas pelas estruturas cognitivas que constituem o habitus, foi que lhe pareceu necessário o estudo dos espaços sociais em que se manifestam essas ações humanas; a teoria dos campos surgiria então como um corolário da adoção da categoria do habitus.

7 ALMEIDA, 2014. p. 81. 


\section{A Noção de habitus na tradição sociológica}

O autor entende habitus como um conjunto de características adquiridas, incorporadas e compartilhadas, de maneira ininterrupta durante todo processo de socialização do sujeito - processo iniciado desde a primeira infância nas unidades familiares (um período decisivo na incorporação da estrutura social e frequentemente desconsiderado pelas teorias da ação racional) até o fim da vida socialmente ativa. Essas características e predisposições, acumuladas de maneira apenas relativamente consciente, ${ }^{8}$ atuam como um filtro cognitivo pelo qual o sujeito avalia questões morais, toma decisões e atua nas esferas sociais em que participa.

$\mathrm{O}$ uso da categoria como foi apresentado, segundo o autor, permitiu-lhe "romper com o paradigma estruturalista sem cair na velha filosofia do sujeito ou da consciência e da economia clássica e do seu homos economicus" ${ }^{\prime 9}$ que tradicionalmente dividiam o campo intelectual no qual atuava. ${ }^{10}$ Por meio da sua recepção, Bourdieu buscou exprimir

8 A nosso ver, não há na obra de Bourdieu um desenvolvimento satisfatório acerca de como se dá esse processo de acumulação psíquica das características que compõe o habitus, sabe-se apenas que os sistemas de percepção da realidade são adquiridos nos processos de socialização do indivíduo e pode-se observar sua concretude por meio de observações empíricas. Uma análise capaz de suprir a questão de um déficit psicanalítico, a partir da teoria crítica, pode ser encontrada em MARCUSE, 1975. De nossa parte, na linha de Bourdieu, estamos mais preocupados com aspectos externos e as consequências sociais das dinâmicas interiores ao campo jurídico e a influência do habitus das elites jurídicas nesse contexto.

9 BOURDIEU, 1989, p. 61.

10 "Uma das funções principais da noção de habitus consiste em descartar dois erros complementares cujo princípio é a visão escolástica: de um lado, o mecanicismo segundo o qual a ação constitui efeito mecânico de coerção de causa externas; de outro, o finalismo, segundo o qual, sobretudo por conta da teoria da ação racional, o agente atua de maneira livre, consciente, [...] sendo a ação o produto de um cálculo das chances e ganhos". BOURDIEU, 
sua recusa consciente "a toda uma série de alternativas nas quais a ciência social se encerrou, a da consciência e do inconsciente, a do finalismo e do mecanicismo" ${ }^{11}$

O autor destaca a falsidade dessas oposições e a explica, a partir de uma intuição que reputa a Pascal: o mundo compreende-me, mas eu o compreendo. A assertiva se vale da polissemia do verbo "compreender", que pode expressar tanto a noção de apreender algo com clareza, quanto o sentido de conter algo dentro de seus limites, para, a partir daí, construir um aparente paradoxo que, no entanto, desaparece numa complexa dialética entre sujeito e objetividade, vejamos: ao mesmo tempo em que o indivíduo está completamente submerso na realidade social e não existe para fora dela e, portanto, essa objetividade o compreende no sentindo que o determina e o limita, ainda assim, por meio de suas representações individuais da objetividade e suas experiências particulares de socialização, a partir desse ponto próprio de compreensão dentro do mundo, o sujeito também compreende a realidade. ${ }^{12}$

Tomando-se essa assertiva como válida, de que apenas é possível compreender a realidade social levando em consideração essa dupla verdade, tanto as teorias objetivistas quanto as teorias subjetivistas pecariam não por serem falsas, mas por não considerarem suficientemente bem o problema em suas duas dimensões, que são, na verdade, inseparáveis. Assim, seria mais correto dizer que as perspectivas teóricas falham ao dividir o indivisível.

O habitus é justamente esse lugar de interseções que o sujeito ocupa no espaço social, ele é influenciado

2001, p. 169.

11 BOURDIEU, 1989, p. 60.

12 "Cada um de nos tem um ponto de vista: ele esta situado em um espaço social e, a partir desse ponto do espaço social, ele vê o espaço social". BOURDIEU \& CHARTIER, 2015, p. 49. 
pelas estruturas presentes na objetividade e pelas relações pessoais de cada trajetória individual e é apenas através dele que os indivíduos interpretam a realidade. É por meio dessa categoria que Bourdieu acredita ter logrado superar as dicotomias objetividade/subjetividade, sociedade/indivíduo, e contribuído para a construção de uma sociologia relacional adequada à descrição do real a partir das particularidades dos objetos observados. Esse processo, de quebra, resgataria a dignidade da disciplina sociológica trabalhada por meio das investigações empíricas.

Essa atitude, de valorização do momento empírico, significou também abdicar da posição do "intelectual total das grandes teorias"13 que, ao desejarem explicar tudo, precisavam assumir tons quase proféticos. ${ }^{14}$ Em oposição a essa perspectiva focada na descrição da "totalidade", Bourdieu procurou contribuir para um novo espírito científico, por meio de "teorias que se alimentem menos da defrontação puramente teórica com outras teorias que do confronto com objetos empíricos sempre novos". ${ }^{15}$

Assim, é preciso aceitar que "é impossível responder a tudo" e, a partir dessa premissa, é necessário responder de maneira satisfatória - ou seja, de acordo com os instrumentos de conhecimento disponíveis e um trabalho científico rigoroso - à perguntas parciais, porém, deliberadamente construídas dessa forma, ainda que sem perder de vista as relações existentes entre a parcialidade e o todo. Essas conexões devem ser feitas com todo cuidado necessário, por

13 Discutindo seu método de pesquisa para construção de gênese e estrutura do campo literário, Bourdieu expressou seu repúdio pela "grande teoria", ao confessar sentir "certa irritação" pelos trabalhos que ambicionam essa categoria. BOURDIEU, 1996, p. 203. O autor retoma essa discussão em BOURDIEU, 1989, pp. 59-73.

14 BOURDIEU \& CHARTIER, 2015, p. 19.

15 BOURDIEU, 1996, p. 204. 
meio da elaboração de abstrações razoáveis de ampliação dos casos concretos estudados, sob o risco de recair, novamente, na armadilha da abstração das grandes teorias.

É exatamente esse tipo de procedimento que acreditamos estar ausente ou pouco representado nas pesquisas jurídicoacadêmicas, em detrimento da hegemonia de investigações teorético-formalistas e da descrição de evoluções normativas no tempo. É preciso buscar apreender as especificidades históricas do campo jurídico e seu funcionamento contemporâneo a partir de análise da objetividade, sem perder de vista a inserção desse espaço social na totalidade capitalista e a influência das diferentes fases e transições desse sistema de produção e reprodução da vida.

Outra importante característica da categoria habitus é que os sujeitos são apenas parcialmente conscientes de sua existência e influência sobre suas ações cotidianas. Ele é fruto de cada experiência econômica, social, cultural, afetiva, etc. pelas quais passaram os indivíduos e permanece inscrito em seus corpos, de maneira mais ou menos oculta, como uma espécie de filtro que atua com uma estrutura perceptiva e avaliativa que condiciona, ainda que não totalmente, todas as ações futuras dos indivíduos.

O habitus é apenas parcialmente desconhecido, pois, por meio de uma atividade reflexiva um sujeito pode vir a reconhecer a forte influência de seus espaços de formação e convívio na sua percepção do mundo, sendo capaz de realizar uma crítica da sua própria posição e admitir, por exemplo, determinados privilégios pessoais como injustificados ou até mesmo vir a modificar determinadas condutas que poderiam ser consideradas uma tendência do seu ser social. Porém, ainda que a possibilidade exista e seja mobilizada por um número razoável de indivíduos, a tendência é que homens e mulheres percebam seus próprios privilégios como naturais ou resultado exclusivo do mérito pessoal. Por fim, 
persiste ainda a possibilidade de o indivíduo reconhecer seus privilégios econômicos, sociais, culturais, de gênero e étnicos e sentir-se confortável com eles, não desenvolvendo qualquer disposição para modificar a situação.

O que é importante ter em mente é que esse exercício reflexivo e essa impulsão à correção de privilégios e preconceitos, ainda que seja uma possibilidade e mesmo um comportamento altamente desejado, não corresponde à tendência das ações humanas. Pelo contrário, agir contra o senso comum requer tempo, formação crítica e disposição para o conflito e, ainda assim, essas ações frequentemente têm resultados muito limitados quando não são acompanhadas por um movimento que as suporte em nível societário.

Esse complexo processo de formação de homens e mulheres ressalta que os indivíduos não escolhem as heranças financeiras, culturais e sociais que lhes são ofertadas pelas unidades familiares e garantidas pelas sociedades nas quais nascem e são formados, nem têm total consciência da inscrição de maneira permanente de determinadas tendências em seus corpos e mentes. Porém, tampouco são completamente determinados por essas condicionantes, visto que efetivamente podem tomar decisões e ações que confirmem ou neguem as tendências dos seus respectivos habitus. No entanto, o fato de se tratar de uma dinâmica complexa, a partir da qual não se pode antever com exatidão matemática as ações dos indivíduos, considerando apenas informações como seu pertencimento de classe ou outros vínculos corporativos como sua atividade profissional, isso também não significa que não possamos traçar padrões de comportamento baseados na observação dos habitus comungados pelos indivíduos em um dado espaço social; uma espécie de lógica do campo.

Assim, ainda que não possamos determinar com certeza como agirá cada magistrado ou magistrada em uma dada situação concreta, apenas conhecendo as características do 
seu habitus respectivo, ainda assim, numa perspectiva mais abrangente, podemos traçar um perfil do comportamento da magistratura como um todo, levando em conta a repetição de padrões no tempo, a homogeneidade social dos indivíduos que a compõe e sua relação com as demais elites dominantes.

Da mesma forma, afirmações como "o campo jurídico brasileiro é conservador e autoritário" podem ser sustentadas por meio da demonstração da permanência dessas características no tempo, constituindo um rígido sentido do jogo que se impõe aos novos integrantes do campo, sem isso significar que todos os agentes que participam desse espaço social reproduzam essas características individualmente.

Pois o habitus, enquanto sistema de disposições de ser e fazer, se manifesta como uma potencialidade, uma espécie de desejo de se concretizar, que, de certa maneira e pelos seus próprios métodos, busca criar as condições de sua própria realização, ou seja, dentro de suas possibilidades, procura "impor as condições mais favoráveis ao que ele é". ${ }^{16}$ É dizer que os agentes fazem o que estiver ao seu alcance para tornar possível ou mais provável a realização, atualização e reprodução das potencialidades que foram escritas em seus corpos durante suas existências.

Isso explica, por exemplo, a tendência de repetição das escolhas profissionais entre gerações, num processo que o filho herda não apenas o conhecimento que lhe é passado pelos pais, mas também toda uma estrutura física e de contatos que são fundamentais ao sucesso na área. Segundo Bourdieu, trata-se de um "princípio decisivo das escolhas cotidianas em matéria de objetos ou de pessoas" ${ }^{17}$

O que Bourdieu sustenta e nos endossamos é que, a partir de uma dinâmica relacionada muito mais a afeições e aversões, simpatias e antipatias, do que a "escolhas racionais", os sujeitos

16 BOURDIEU, 2001, p. 182.

17 BOURDIEU, 2001, p. 183. 
que comungam habitus semelhantes tendem a se comportar de maneira mais ou menos homogênea - observação de certas regras de etiqueta, ou não, modo de falar, vocabulário, etc. -, além de escolher objetos semelhantes - modelo de carros, casa, espaços ocupados na cidade, etc. Em suma, “observa-se uma espantosa sintonia entre as características e disposições dos agentes as dos objetos de que eles se cercam ou das pessoas com as quais eles se associam de modo mais ou menos duradouro - cônjuges, amigos, relações" ${ }^{18}$

Ohabitus tende a construir disposições que fazem com que os sujeitos ajam em benefício de sua reprodução e valorização, consequentemente, valorização das potencialidades do próprio indivíduo que possui as características desse habitus específico. Isso é especialmente verdade para os sujeitos que compõe as elites do poder, pois, soma-se a valorização de seu habitus por meio da ação de seus próprios integrantes, a atuação daqueles indivíduos que almejam ingressar nessas esferas e, como estratégia de ascensão social, passam a emular as características ali presentes. ${ }^{19}$ Assim, é extremamente comum, entre os indivíduos que compõe as elites do poder e aqueles desejosos de entrar para seus círculos, a tendência pela escolha de estratégias de ação que não confrontem um status quo que lhes garante e mantém enormes privilégios. É nesse sentido que entendemos que esperar uma postura social progressista da magistratura brasileira, considerando sua origem aristocrata e atual perfil econômico e social, é

18 Para mais sobre as distinções e aproximações relacionadas com juízos estéticos ver BOURDIEU, 2007.

19 Trata-se de um saber, aliás, bastante recorrente em produções estéticas populares, como na letra de Quem e ninguém, do cancioneiro pernambucano Sérgio Roberto Veloso de Oliveira, o Siba, na qual se lê “Quem tudo tem se mantém / Quase sempre inacessível / Por Sempre ter disponível / Em cada esquina um alguém / Que está contente também, arrodeando o poder / E até mesmo tem prazer / Toda vez que bota o pé / No pescoço de um mané / Que também sonha em crescer". 
uma atitude senão utópica formal, bastante contra-intuitiva; sempre poderá ser possível na ordem do imaginável, mas dificilmente pode ser chamado de tendência (utopia objetiva).

O mais importante é entender que possuir um habitus específico não significa ter suas escolhas completamente determinadas por esse, porém, o fato de sempre se estar condicionado a uma série de filtros de cognição da realidade - condição inerente ao ser social do homem - inviabiliza enquanto falsas as teorias mais extremas da escolha racional. ${ }^{20}$

Em suma, o habitus é uma espécie de repositório de experiências que espontaneamente e inconscientemente é utilizado pelos sujeitos como referência para avaliação das variantes externas que se apresentam em um dado caso concreto, visando a escolha de uma ação - ou não ação em um cenário específico; “é um esquema de conduta e comportamento que passa a gerar práticas individuais e coletivas" de maneira não necessariamente consciente e é exatamente por ser "espontaneidade sem consciência ou vontade" que "o habitus não se confunde com a necessidade mecânica, nem com a liberdade reflexiva dos sujeitos das teorias racionalistas" 21 .

20 Segundo Patrick Baert (1997, p. 1-3), a teoria da escolha racional é definida como a teoria sociológica que se propõe a explicar o comportamento social e político assumindo que as pessoas agem racionalmente. Sua relevância no curso dos anos 1980, portanto, concomitante à expansão e hegemonização da razão neoliberal nas democracias liberais, significou "o último assalto imperialista da economia na sociologia". Algumas limitações das explicações da escolha racional na ciência política e na sociologia. Em sentido contrário, entendendo que as teorias da escolha racional não são teorias normativas e que os agentes desviam sim do que prescreveria a racionalidade, mas, "mesmo não agindo racionalmente, as pessoas tendem a reconhecer a força normativa da racionalidade, e isso influencia as suas ações - que se aproximam ao menos um pouco daquilo que criaturas de racionalidade ideal fariam nas mesmas circunstâncias.", ver FEREJOHN \& PASQUINO, 2001, p. 6.

21 SOUZA, 2012, p. 46. 
Por tudo que foi exposto, a categoria do habitus nos parecer a mais adequada para enfrentar questões acerca de como agem as elites do campo jurídico no Brasil, sobretudo pensando na atuação dos magistrados e magistradas, dentro do campo jurídico e para além dele, por meio de suas excursões nem sempre legítimas nos campos da política e da moral. Isso por que permite identificá-los enquanto um grupo de indivíduos mais ou menos homogêneo que tendem a compartilhar uma visão do mundo semelhante e a buscar estratégias de ação igualmente parecidas; e isso sem desconsiderar suas eventuais divisões em frações - sejam cortes horizontais que distingam funções, como as diferenças entre magistrados, promotores, advogados e professores, ou cortes verticais que consideram as diferenças entre magistrados e magistradas de primeira e segunda instâncias -, além de não descartar a distinção entre grupos dominantes e dominados dentro do campo jurídico.

É importante destacar que, os grupos da elite jurídica não constituem uma "classe", ao menos não no sentido estritamente objetivista de certa tradição marxista da categoria $^{22}$ - ou seja, centrada na distinção entre burgueses e proletários segundo a posse ou não dos meios de produção ${ }^{23}$

22 Em oposição a uma concepção estritamente objetivista de classe no marxismo ver o tratamento da categoria em BOITO JUNIOR, 2007, pp. 201 e ss. Para um aprofundamento no tema ver POULANTZAS, 2007(1968).

23 A compreensão dos juristas enquanto classe nos termos tradicionais levaria a generalizações pouco justificáveis como uma indiferenciação entre as elites jurídicas, política e econômica enquanto burgueses. Poderia conduzir ainda a equívocos frutos da crença de que, por constituíssem a mesma classe, esses sujeitos possuíssem os mesmos interesses e disposições; o que efetivamente não acontece. A elite jurídica, em função de organizar-se formalmente "com base na competência exigida para cada cargo", constitui um lugar de emprego privilegiado da classe média alta (ou tradicional) e, a depender da conjectura sócio-histórica do momento, pode atuar enquanto representante político das classes médias, sem deixar sua exercer sua função na burocracia do Estado. Na leitura de Armando Boito Junior, por exemplo, o que vimos iniciar-se (intensificar-se, talvez fosse mais preciso) 
-, mas podem ser considerados enquanto classe na leitura bourdieusiana.

Vale destacar, no entanto, que o conceito de classes no marxismo é muito mais complexo e dinâmico que as visões reducionistas que o enxergam apenas como uma clivagem estanque entre burguesia e proletariado ${ }^{24}$ como faz Bourdieu ao criticá-lo dentro do bojo das teorias ditas estritamente objetivistas. A categoria comporta ainda inúmeras variações no interior de uma mesma classe, em frações com constituição e interesses distintos - como as dicotomias entre a burguesia nacional e integrada, diferentes estratos de classes médias, as diferenças entre o proletariado e o lumpemproletariado etc. ${ }^{25}$

A sociologia relacional, porém, procura superar tanto as teorias objetivistas quanto as teorias subjetivistas ao entender as classes sociais em suas duas dimensões complementares, a saber, "na objetividade de primeira ordem, aquela registrada pela distribuição das propriedades materiais" e "na objetividade de segunda ordem, aquela das classificações e das representações contrastantes que são produzidas pelos

no âmbito da operação Lava-jato, foi uma associação tática entre uma burguesia financeira-integrada ao imperialismo e a elite jurídica, utilizando politicamente o combate à corrupção por meio do sistema de justiça para desconstruir a hegemonia construída pela burguesia industrial-nacional durante os anos do Partido dos Trabalhadores. BOITO JUNIOR, Armando. Lava-jato, classe média e burocracia do Estado, v. 2, n. 3, 2017.

24 Basta que resgatemos o complexo diagnóstico da luta de classes na França, descrito pelo próprio Marx em O 18 de Brumário. Na oportunidade, contamse inúmeras classes sociais que se posicionam nas disputas sem relação imediata com seus interesses econômicos, como no caso dos republicanos, que eram burgueses não pelo seu vínculo econômico, mas em função de sua visão de mundo. MARX, 2011.

25 "É nesse sentido que as classes podem ser vistas como processos vivos e em movimentos conflituosos, ou melhor, como produtos de um conjunto de estruturas relacionadas com as esferas econômicas, políticas, culturais e ideológicas." POCHMANN, 2014. 
agentes com base no conhecimento prático das distribuições tal como se manifestam nos estilos de vida". ${ }^{26}$

O próprio Bourdieu reconhece a diferença entre as manifestações do marxismo hegemônicas na França ao seu tempo - vistas como formas "estritamente objetivista" que assume essa tradição, "o mais das vezes" 27 - e a obra propriamente marxiana. No mesmo sentido, Loïc Wacquant entende que a abordagem do sociólogo francês incorpora uma concepção marcadamente relacional da vida social, no mesmo sentido de Marx e Durkheim, mas que divergia da abordagem marxista e weberiana de classe, ressurgentes durante os anos 1970, ao mesmo tempo em que se aproximava de Weber ao por as lutas e disputas, e não a reprodução, como centro do seu sistema. ${ }^{28}$

Sua abordagem das classes singulariza-se, no entanto, pela "ênfase colocada na dimensão e nos mecanismos simbólicos da formação e da dominação de grupo" ${ }^{29}$ Nesse sentido, as elites jurídicas podem ser consideradas um classe, uma vez que existem em função de uma distribuição desigual de capitais (na objetividade de primeira ordem) e são reconhecidas (na objetividade de segunda ordem) em meio a disputas permanentes pela imposição de sistemas e categorias de percepção que conformam a realidade social e influenciam no reconhecimento de sua própria representação.

No sentido dado pela sociologia bourdieusiana, "classe" deixa de ser referenciada exclusivamente em relação à posse de propriedade - ainda que essa dimensão mantenha sua importância - e passa a ser entendida, sobretudo, com fundamento na observação de "práticas sociais similares, que

26 BOURDIEU, 2013, p. 111.

27 BOURDIEU, 2013, p. 107.

28 WACQUANT, 2013, p. 88.

29 WACQUANT, 2013, p. 89. 
permitem estratégias comuns e consequências compartilhadas mesmo na ausência de acordos conscientes e refletidos". ${ }^{30}$

Esse instrumental teórico permite compreender como o resultado da soma das ações individuais dos agentes inseridos no campo jurídico tende a representar, na esmagadora maioria das vezes, uma importante força de conservação das relações sociais como estabelecidas, independente das vontades individualmente consideradas, dos discursos públicos, e das tentativas de utilização do direito como ferramenta de transformação social.

No último caso, as propostas de explorar as contradições do sistema por dentro dos espaços jurídicos constituem táticas importantíssimas para intervenção na realidade imediata e são encampadas por frações minoritárias e dominadas do campo. Infelizmente e independentemente das boas vontades envolvidas, essas estratégias findam por contribuir para a legitimação do campo como estabelecido, ao dar a impressão de tratar-se de um espaço de disputa justa entre diferentes interpretações das normas jurídicas quando, na realidade, mais se aproxima de um jogo de carta marcadas.

Não obstante suas importantes diferenças apontadas, esse modelo descritivo parece antes complementar do que se opor a intuição desenvolvida pelo marxismo ocidental acerca da relação entre a ciência e os cientistas e a sociedade capitalista, expressa, entre outros, por Horkheimer em seu célebre texto considerando fundante da escola de Frankfurt. Para essa tradição do pensamento, o trabalho dos cientistas no contexto do capitalismo tardio - naturalmente, também o trabalho dos juristas tradicionais - tende a constituir um momento de reprodução das relações como estabelecidas por meio da confirmação continua do já existente, independente daquilo que imaginam a respeito disso. ${ }^{31}$

30 SOUZA, 2012, p. 57.

31 HORKHEIMER, 1991. 
Vencida essa primeira etapa, sobre os filtros de julgamento - sistemas de cognição, percepção e valores - que influenciam as tomadas de decisão dos agentes, denominado habitus, é preciso agora nos dedicar aos espaços sociais nos quais as ações dos agentes acontecem, os campos sociais. Nosso objetivo na próxima seção é destacar como surgem os campos sociais - por meio de um processo de diferenciação em relação aos demais espaços sociais -, descrever as interações entre esses diferentes espaços sociais e introduzir a discussão acerca dos limites da autonomia de cada uma dessas esferas individualmente consideradas. Nessa reconstrução privilegiaremos exemplos demonstrativos retirados das dinâmicas do campo jurídico, como forma de ressaltar que esses espaços são uma manifestação particular e concreta da teoria dos campos.

\section{A noção de campo e o campo jurídico brasileiro}

Em um texto de intervenção acerca do campo científico, dedicado a audiência dos pesquisadores do Institut National de la Recherche Agronomique, Bourdieu sintetizou com clareza a noção de campo e as necessidades empíricas que o conduziram ao uso dessa categoria. Por essa razão iniciamos nossa exposição com a realização de comentários acerca de enxertos dessa apresentação.

A noção de campo esta aí para designar esse espaço relativamente autônomo, esse microcosmo dotado de leis próprias. Se, como o macrocosmo, ele é submetido a leis sociais, essas não são as mesmas. Se jamais escapa às imposições do macrocosmo, ele dispõe com relação a este, de uma autonomia parcial mais ou menos acentuada ${ }^{32}$.

A chave da passagem transcrita éo termo "relativamente autônomo" ou "autonomia parcial", significando que as

32 BOURDIEU, 2004, p. 20-21. 
produções culturais (entre elas o direito), apesar de jamais escaparem das interferências do macrocosmo - que são justamente o conjunto dos demais campos sociais, sobretudo o econômico, em se considerando sociedades capitalistas -, ainda assim, mantêm alguma esfera da autonomia.

Essa autonomia é manifestada pela capacidade do campo estabelecer e fazer valer leis próprias de sua reprodução, que vão desde as condições de entrada e recrutamento dos indivíduos que atuam dentro de seus limites até a capacidade de estabelecer suas dinâmicas e procedimentos particulares de funcionamento. A principal característica dos campos é a distribuição desigual dos recursos que gera uma situação de hierarquia e dominação dentro desses espaços que, por sua vez, conduz a disputas entre os agentes pela modificação ou manutenção da distribuição desses recursos. ${ }^{33}$

Por outro lado, o que singulariza cada campo é a busca da realização de sua finalidade específica por partes de todos que possuem habilitação para movimentar-se legitimamente nesses espaços sociais. Porém, ao mesmo tempo em que buscam a realização da finalidade do campo, os agentes constroem e reforçam também os seus próprios interesses, de maneira mais ou menos consciente, o que favorece que as dinâmicas particulares dos campos apareçam para os profanos $^{34}$ como naturalizadas.

Assim, colaborar voluntariamente com as dinâmicas de um campo específico, estabelecidas previamente a entrada de novos agentes (estruturas estruturadas), é participar de

33 TARGA, 2017, p. 27.

34 Bourdieu frequentemente utiliza o termo "profanos", em oposição aos profissionais, para designar os demais membros da sociedade que são não estão habilitados a atuar no campo especificamente considerado. No caso do campo jurídico, todos aqueles não possuidores de um diploma em direito, portanto, não oficialmente habilitados a atuar no campo, constituiriam os chamados profanos. 
uma espécie de ilusão (illusio) ou jogo, feito por meio de práticas que são potencialmente estruturantes desse mesmo campo. É dessa forma que ações de agentes antagônicos de um lado, grupos que pretendem manter a doxa, e, do outro, indivíduos interessados na modificação das regras do jogo, possuem na illusio seu ponto em comum: "todos reconhecem o jogo como importante". ${ }^{35}$

Aceitar e pautar-se rigidamente em referência a essas leis, artificialmente construídas, sem nunca questionar-lhes a origem ou a validade, garante uma espécie de naturalização das instituições, como se o estado nas quais se apresentam na objetividade presente fosse fruto do melhor desenvolvimento possível dessas estruturas no tempo.

Participar da ilusio, científica, literária, filosófica, ou qualquer outra, é o mesmo que levar a sério os móveis dessa competição os quais, nascidos da lógica do próprio jogo, conferem seriedade ao jogo, ainda que possam escapar ou parecer "desinteressados" e "gratuitos" àqueles que por vezes são chamados de profanos ou àqueles envolvidos em outros campos ${ }^{36}$.

Quando se considera especificamente o campo jurídico é importante perceber que a complexa dinâmica de procedimentos formais, por vezes, aparentemente caótica, na qual entram em disputas diferentes agentes habilitados por diplomas e nomeações estatais, em busca de determinar o que é o direito; essa complexa dinâmica é imprescindível para que os interesses individuais, ou seja, as interpretações morais e as influências externas (sobretudo políticas e econômicas) que efetivamente incidem sobre esses processos, não raras vezes como fatores determinantes, apareçam para o restante da sociedade como o contrário do que realmente são: como resultados exclusivamente racionais, no caso, técnico-jurídicos.

35 TARGA, 2017, p. 29.

36 BOURDIEU, 2001, p. 21. 
A relação entre os espaços sociais constituídos e os habitus dos indivíduos, discutido previamente, se dá em função da presença, no interior dos campos, do que Bourdieu chama de "sentido do jogo", a saber, um estado incorporado "sob a forma de um habitus específico" que "jamais é posto ou imposto de maneira explícita" ${ }^{37} \mathrm{O}$ que chamamos de habitus específico "não é outra coisa senão um modo de pensamento particular (um eidos)" ${ }^{\prime 38}$ resultado de uma construção contingencial do social, fundada na crença préreflexiva do valor indiscutível dos processos de construção e dos objetos construídos. Portanto, na medida em que existe um habitus individual, inerente aos processos de formação de cada sujeito, existe também um habitus específico de cada campo cultural, desenvolvido historicamente no interior desse espaço social.

Esses dois habitus podem tanto vir a se confirmarem reciprocamente quanto se chocarem um com o outro, produzindo diferentes resultados sobre como se comporta um indivíduo no interior dos seus espaços de socialização. Assim, possuir em seu habitus, individual e originário, disposições e inclinações que já estão presentes no habitus específico que se adentra, pode ser uma importante condição de sucesso nesse campo:

Na realidade, em lugar do habitus tácita ou explicitamente exigido, o novo postulante deve trazer para o jogo um habitus praticamente compatível, ou suficientemente próximo, e acima de tudo maleável e suscetível de ser convertido em habitus ajustado, em suma congruente e dócil, ou seja, aberto à possibilidade de reestruturação. É a razão pela qual as operações de cooptação prestam atenção aos sinais de competência e ainda mais aos indícios quase imperceptíveis, quase sempre corporais, postura, compostura, maneiras, disposições de ser e sobretudo de vir a ser, quer se trate de escolher um jogador de rúgbi, um professor, um

37 BOURDIEU, 2001, p. 21.

38 BOURDIEU, 2001, p. 121. 
alto funcionário ou um policial ${ }^{39}$.

$\mathrm{Na}$ passagem, Bourdieu destaca que, para além dos sinais de competência (da capacidade de realização de um bom trabalho), os traços quase imperceptíveis, incorporados aos corpos daqueles que almejam entrar no campo, podem ser ainda mais importantes na determinação dos processos de seleção, entrada e promoção. A verificação de tais características mediante, por exemplo, a realização de bancas de concurso, compõe parte das estratégias apenas parcialmente conscientes de reprodução do campo, ao garantir que nele adentrem apenas aqueles que estão, no mínimo, suscetíveis de serem adaptados (habitus maleável ou suscetível) ao sentido do jogo que está previamente estabelecido. Trata-se de requisitos que não são reconhecidos nem oficialmente nem publicamente, mas que têm efeitos concretos, por vezes, determinantes, na aprovação em provas de concursos - desde as provas de acesso a função de professor do ensino público superior às provas de acesso à magistratura ou à promotoria pública.

É, em parte, por meio dessas estratégias que o campo jurídico consegue homogeneizar, sem o dispêndio aparente de energia, toda uma série de comportamentos que vão desde a maneira de se vestir e falar ${ }^{40}$ até a incorporação de determinados valores e percepções que são compartilhados dentro das instituições jurídicas as quais os indivíduos aspiram ser admitidos. Nesse sentido, ainda durante a graduação - e

39 BOURDIEU, 2001, p. 121.

40 Não são raros os casos de reprimenda de vestuário nas cortes brasileiras, indo desde a proibição de acesso aos prédios oficiais até casos mais emblemáticos como o acontecido no mês de Agosto de 2017, em Goiânia. Na oportunidade, o desembargador Eugênio Cesário interrompeu julgamento por sentir-se ofendido com a roupa da advogada que fazia sustentação oral, ameaçando, inclusive, deixar a sessão caso a profissional não trocasse de roupa. Disponível em: https://g1.globo.com/goias/noticia/desembargadorameaca-deixar-audiencia-por-causa-da-roupa-de-advogada-video.ghtml. Acesso em 21 de setembro de 2017. 
até mesmo antes disso, para aqueles sujeitos que advêm de núcleos familiares das elites jurídicas - vai se impondo aos estudantes a incorporação de um vocabulário específico, uma maneira de postar-se em público, de vestir-se e certas concepções de mundo que são específicas do campo jurídico.

Do lado oposto, possuir disposições que conflitam com as dinâmicas já estabelecidas pode demandar uma necessidade de adaptação pela incorporação, por vezes violenta, das características dominantes no espaço social em que se pretende atuar, ou pior, quando presente a disposição para lutar contra o sentido do jogo, o campo dispõe de métodos para penalizar o agente, que vão desde a discreta negação dos canais de promoção e reconhecimento até a perseguição institucional.

Em outra oportunidade, ${ }^{41}$ constatamos que o campo jurídico brasileiro, desde sua origem, constituí-se em um espaço historicamente hegemonizado pelos herdeiros das elites do poder, especialmente homens e brancos. Ainda que a participação do gênero feminino nas instituições jurídicas venha crescendo nos últimos anos, a sua incorporação não ameaça a hegemonia masculina nas posições dominantes do campo, como nos Tribunais Superiores.

Em relação à questão racial, apesar de negros e negras representarem a maior parcela da população brasileira, não chegam a $15 \%$ de nossos magistrados e magistradas e têm sua representação diminuída a cada passo que subimos na hierarquia profissional do judiciário. ${ }^{42}$

Naquela oportunidade, concluímos que:

Os indivíduos que apresentam, em suas estruturas mentais, corporais e de expressividade, as características tradicionais do campo jurídico - gênero masculino, pele branca, educação religiosa

41 CASTRO, 2018.

42 CASTRO, 2018, p. 54. 
cristã, orientação heterossexual etc.-, traços frequentemente garantidos por nascimento e por um processo de formação mais ou menos homogêneo, do qual participam quase que exclusivamente os filhos das elites nacionais; esses sujeitos têm mais possibilidades de sucesso (progressão e reconhecimento) no campo jurídico nacional do que aqueles que, diferentemente, não possuem essas características. Em síntese, essas condições são critérios não reconhecidos, mas concretos, de progressão nas carreiras jurídicas, sobretudo na mais antiga delas, a magistratura. ${ }^{43}$

A nosso ver, esse tipos de observações empíricas permitem verificar na prática a manifestação do sentido do jogo conservador do campo jurídico nacional, presente desde sua gênese; o que possibilita a compreensão mais adequada das dinâmicas sociais desses espaços; situada nalgum lugar entre as escolhas racionais livres, as condicionantes impostas pelo habitus do agente e as determinações sociais que lhes são externas.

Segundo Bourdieu - a nosso ver, de certa forma, superdimensionando sua originalidade -, antes da elaboração de sua gramática sociológica, persistia em todas as produções culturais, da filosofia à literatura, naturalmente passando pelo direito, uma tendência dos cientistas sociais a optarem por um dos pólos de uma aparente oposição irredutível: a escolha entre as explicações internas e as explicações externas sobre a dinâmica dos campos sociais.

Enquanto as primeiras tendiam ao fetiche do texto, entendendo pela autonomia absoluta da área de pesquisa considerada, a segunda tendia ao fetiche da heteronomia, ou seja, a explicação por meio exclusivo de forças externas que incidem sobre o objeto considerado, notadamente, sobredimensionando as relações de produção. A primeira corrente teria florescido na França com a semiologia e

43 CASTRO, 2018, p. 55. 
regressaria naquele momento (1997) na forma das mais variadas tipologias do pós-modernismo. A segunda seria representada, como se pode supor, pela tradição marxista que se propõe a interpretar as obras colocando-as em relação de subordinação com o mundo social e econômico. ${ }^{44}$

Assim, a exemplo da possibilidade de escapar do falso dilema entre as concepções objetivistas e subjetivistas da ação humana por meio da noção de habitus, Bourdieu desenvolve a noção de campo para superar a oposição entre as teorias internas e externas de explicação da lógica das produções culturais. Nesse sentido, a partir da ideia simples de que "para compreender uma produção cultural não basta referir-se ao conteúdo textual dessa produção, tampouco referir-se ao contexto social contentando-se em estabelecer uma relação direta entre texto e contexto" 45 , Bourdieu defende que é necessário considerar a dialética entre as referências internas e externas de uma dada produção cultural. O autor sustenta então que, entre texto e contexto, existe um campo social que obedece a leis sociais mais ou menos específicas e que entra em relação com os demais espaços sociais que constituem a totalidade do social.

Retomando ao acento sobre a questão da autonomia relativa, como a propugna Bourdieu, os campos a apresentam [a autonomia] em graus muito variados, a depender de determinadas características específicas de cada campo, bem como de aspectos temporais e geográficos. Um dado campo pode, com efeito, ser mais ou menos autônomo: (i) em relação a outros campos num mesmo contexto territorial, (ii) em relação ao seu passado específico ou, ainda, (iii) em relação ao seu espaço social análogo considerado numa realidade comparada. Nesse sentido pode-se levantar hipóteses de (a) que o campo

44 BOURDIEU, 2004.

45 BOURDIEU, 2004, p. 19. 
político brasileiro é mais autônomo frente ao campo jurídico que ao campo econômico, (b) que o campo jurídico no Brasil hoje é mais autônomo frente ao campo político que nos tempo coloniais ou (iii) que o campo jurídico francês é mais autônomo do que o campo jurídico brasileiro, entre outras inferências possíveis que, naturalmente, demandam comprovação.

Essa proposição, apesar de parecer um pouco óbvia, é fundamental para a análise sociológica dos campos sociais nacionais. É dizer que não é possível tomar o diagnóstico desenvolvido por Bourdieu sobre o campo jurídico na França e esperar aplicá-lo à realidade brasileira sem atentar para as particularidades locais que modificam as estruturas e condições estruturantes.

De toda forma, esse método de pesquisa desenvolvido por Bourdieu para subsunção das produções culturais à sua análise sociológica pode ser aplicado aos demais campos culturais, desde que com a devida vigilância epistemológica para compreensão das particularidades específicas de cada área na construção dessas descrições: dos campos especificamente considerados, dos habitus dos seus agentes e o tipo de capital que se encontra em disputa nesses espaços por esses sujeitos.

O campo jurídico, portanto, se constitui ao construir sua autonomia parcial ou relativa, quando passa a ser capaz de estabelecer suas regras próprias de reprodução e quando elabora um espaço social exclusivo de disputa pelo capital jurídico por sujeitos habilitados a tanto. No que concerne a Europa Ocidental, objeto de pesquisa de Bourdieu em seus cursos Sobre O Estado e em A Nobreza do Estado ${ }^{46}$, esse processo se dá simultaneamente a constituição do Estado moderno. Naquele contexto, os juristas contribuíram para fundação da ficção jurídica do Estado ao mesmo tempo em que criaram

46 BOURDIEU, 2013. 
para si um espaço exclusivo de ação e se constituem enquanto classe. No caso nacional, o campo jurídico apenas terá sua elaboração iniciada a partir da independência e da fundação das primeiras escolas jurídicas no Brasil. A nosso ver, antes desse período o campo jurídico não logra se desprender da experiência portuguesa. ${ }^{47}$

A autonomia dos campos jurídicos, em qualquer contexto (ontem e hoje, na Europa, nos EUA ou no Brasil), será sempre relativa - aliás, assim como são apenas parcialmente autônomos os demais campos sociais. Porém, em função de contingências históricas, o campo jurídico nacional é especialmente interdependente dos campos político e econômico, muito em função da homogeneidade existente entre suas elites, como veremos oportunamente. Os processos de interações entre os diferentes espaços sociais produzem interferências capazes de influenciar a tomada de ações no interior dos campos afetados, de tal forma que não existe uma autonomia completa de nenhum espaço social individualmente considerado, ainda que alguns deles tendam a ser mais independente (campo artístico) ou menos independente (campo jurídico).

Em suma, o campo jurídico é uma manifestação particular da teoria dos campos sociais - assim como o são os campos político, econômico, educacional, cultural, etc. - que representa o espaço de mobilização disponível aos diferentes agentes portadores das habilitações adequadas - desde a matrícula numa faculdade de Direito a posse de função pública, passando pelo título de bacharel - e no qual se dá disputa e concorrência pelo poder de dizer o Direito, ou seja, de determinar dentro da semântica dos possíveis a interpretação das normas que efetivamente se concretizará e produzirá efeitos na objetividade.

47 CASTRO, 2018, p. 224 e ss. 
Parte-se da premissa de que o campo jurídico, genericamente definido como um universo de interação dos bacharéis em direito, implica num espaço socialmente instituído por ritos, símbolos, códigos, hierarquias, e garantias legais legitimadas pelo Estado. A apreensão dos princípios de sua estruturação envolve a análise de variáveis que explicitem a estrutura dos capitais mobilizados na sua hierarquização e a relação dos agentes com essa estrutura ${ }^{48}$.

Dessa forma, para compreender o funcionamento do campo jurídico é imprescindível conhecer a dinâmica histórica de sua construção, a interação entre os indivíduos e as estrutura interiores ao campo, seus objetivos esperados e ofertados, a mobilização dos diferentes tipos de capitais acumulados por esses sujeitos para obtenção desses resultados, bem como a homogeneidade ou heterogeneidade entre os habitus que desfrutam os agentes jurídicos coletivamente considerados.

O resultado da comunicação específica que se dá no campo jurídico é a expressão por excelência do poder simbólico, tipo específico de manifestação de poder capacidade de submissão dos indivíduos a uma determinada vontade - que é marcada pela possibilidade de "produzir efeitos reais sem dispêndio aparente de energia".$^{49} \mathrm{O}$ direito realiza esse papel por meio das suas características particulares de intervenção na realidade social - a linguagem jurídica cria, conserva ou modifica as visões oficiais de mundo por meio dos seus poderes de nomeação, garantidos pela chancela estatal - e, assim, logra ser reconhecido e aceito como se fosse independente de outras formas de poder e arbítrio, que, no entanto, estão efetivamente presentes na sua gênese.

É dito sem dispêndio "aparente" de energia, pois a aceitação coletiva de um ato final de interpretação judicial normalmente ignora todo processo de disputas sociais travadas no passado e em constante movimento, que

48 ENGELMANN, 2006, p. 17.

49 BOURDIEU, 1989b, p. 15. 
conduziram a estruturação do sistema judicial na forma específica na qual um órgão particular - um juiz monocrático, uma turma de desembargadores ou um tribunal superior - é competente para decidir em termos finais um dado conflito. Ademais, prescinde apenas aparentemente de energia, pois, a todo tempo persiste subjacente ao comando jurídico a ameaça do recurso a violência policial para cumprir o conteúdo das decisões.

Tais veredictos não se sustentam exclusivamente na vontade individual ou coletiva dos magistrados, como se essas vontades pudessem ser impostas mecanicamente sobre os demais agentes jurídicos. Antes, a efetividade das interpretações conta com uma adesão implícita de todos os participantes do campo ao sentido do jogo e, por meio da aceitação dos especialistas - teoricamente os indivíduos em melhor posição para compreender o Direito - logra, em alguma medida, obter o consenso tácito do restante da sociedade (os profanos).

Para obtenção dessa adesão - ou pelo menos para garantir certa estabilidade nas suas decisões - os juízes devem se movimentar dentro de um repertório limitado de argumentos jurídicos reconhecidos pelo campo enquanto tais - jurisprudências, doutrinas nacionais e estrangeiras, direito comparado etc. Os demais juristas, desde bacharéis a professores, passando por advogados e promotores, também participam dessa dinâmica, cada um a sua maneira e com seu peso relativo - considerado em relação com os demais agentes do campo. Contribuem por meio de suas ações na atualização permanente das possibilidades interpretativas do Direito, espaço no qual se movimentam os magistrados.

Esse processo de co-participação na elaboração dos limites da interpretação jurídica no interior do campo, ainda que não se estabeleça em um regime de igualdade, auxilia na construção da adesão coletiva dos agentes jurídicos que dele 
participam e, consequentemente, de toda a sociedade "leiga", que tende a enxergar esses processos como resultados da aplicação da melhor técnica jurídica pelos experts.

Isso não significa que os juízes estejam absolutamente presos a esse repertório ou que não atuem fora das razões jurídicas, mas auxilia a dar a aparência de que o fazem, mesmo quando, na verdade, decidem muito mais em função de motivações políticas ou de convicções pessoais. Com efeito, existem teorias da decisão judicial que defendem interpretações mais livres das normas, que lhes permitem extrapolar e inovar no campo, o que, por sua vez, já inicia um processo de remodelagem dos limites do próprio campo, no sentido de que essa nova decisão passa a compor jurisprudência para interpretações futuras.

Ainda que a prerrogativa do livre convencimento seja garantida, em tese, a todos os magistrados, obviamente nem todos possuem a mesma capacidade de fazer confirmar a sua interpretação sobre o campo. Juízes de primeira instância podem ser reformados por seus colegas das instâncias superiores e assim sucessivamente numa corrente hierárquica que tem como cume o plenário do STF. Assim, os magistrados que possuem posições de elite, em função da acumulação de capital político, cultural e social ao longo de suas trajetórias individuais, naturalmente, têm maior poder de conformação sobre o campo jurídico. Dessa forma, um ministro do STF tem mais condições de fazer valer a sua interpretação sobre as normas jurídicas que um desembargador de um Tribunal Regional, que, por sua vez, tem maiores possibilidades de influência sobre o campo que o magistrado de primeira instância.

Toda essa dinâmica significa que o poder simbólico não reside meramente na estrutura dos símbolos, mas antes nas relações entre os que exercem poder e aqueles que lhes estão sujeitos. 
Assim, o ato final de interpretação judicial, que produz efeitos na realidade objetiva, para obter o consenso público necessário a produzir obediência, depende de uma série de atores e estruturas - advogados, partes, técnicos administrativos, instituições públicas como Ministério Público e a Ordem dos Advogados, além das garantias processuais do devido processo legal - que "crêem" no poder simbólico do direito. ${ }^{50}$

Em suma, o poder simbólico expresso pela linguagem do direito, garantido e endossado pelos aparelhos estatais que cercam todo o processo, consolida uma única resposta, dentre muitas possíveis, como reconhecidamente justa e correta para aquele caso concreto - isso seja em uma concepção substancial de justiça, caso entenda-se que a racionalidade jurídica efetivamente permita apenas uma resposta correta, ou em uma concepção procedimental, na qual a observância de uma série de ritos oficiosos é a própria concretização da justiça possível. Dessa forma, a gênese política do direito, expressa nas disputas existentes pela determinação do conteúdo final da norma - e, originalmente, na consolidação do próprio Direito durante os processos constituintes e de reformas - desaparece para dar lugar a uma linguagem neutra e técnica, expressão por excelência do poder simbólico.

Compreender o campo jurídico como um espaço social de disputa, onde agentes habilitados, portadores de

50 Ao tratar sinteticamente sobre o poder simbólico em termos gerais, Bourdieu defende que "o que faz o poder das palavras e das palavras de ordem, poder de manter a ordem ou de a subverter é a crença". BOURDIEU, Pierre. Sobre o poder simbólico. Ob. Cit., p. 15. Isso significa que o poder simbólico, esse que prescinde inicialmente da violência física, depende necessariamente do consenso daqueles que lhes estão submetidos para garantir sua efetividade. Quanto maior for essa crença, tendem a ser mais estáveis as posições dominantes na sociedade considerada. No sentido contrário, quanto menor for essa crença, ou seja, quanto maior for a disposição da sociedade para questionar a legitimidade dos poderes constituídos, mais será a tendência de utilização do recurso à violência física das forças policiais e militares. 
inclinações, vontades e interesses diversificados, concorrem pelo monopólio de determinar os sentidos da linguagem jurídica, inicialmente, parece distanciar-se das abordagens marxistas que tendem a enxergar a forma jurídica como mero reflexo da forma econômica. Porém, admitir uma concepção concorrencial, tão pouco implica reduzir o direito a meras relações de comunicação justa, onde a dominação estaria ausente. É necessário entender que essa comunicação se dá em estruturas histórica e desigualmente constituídas e que as estratégias de reprodução dos agentes, não raramente, dependem da acumulação de capitais que são alheios à lógica parcialmente autônoma do campo.

Portanto, as produções simbólicas, dentre as quais está inserido o Direito, possuem tanto a função social integrativa, ao contribuírem para o estabelecimento das bases da comunicação social, como também exercem função política de dominação e conservação da ordem, quando servem a interesses particulares que tendem a apresentarem-se como universais, a saber, os interesses das elites do poder em controle do aparelho estatal.

Em determinados contextos, como nos parece ser o caso brasileiro, em função de um passado histórico que nunca rompeu de maneira significativa com estruturas anteriores de dominação (da escravatura às ditaduras) e que manteve uma clara continuidade no habitus de suas elites do poder (com uma forte homogeneidade entre as elites política, econômica e jurídica) é possível afirmar que o campo jurídico sempre exerceu mais sua função política de conservação do status quo em detrimento das funções integrativas ou transformativas da realidade social. Isso importa considerar que o campo jurídico pode ter funções distintas em realidade comparadas, bem como, eventualmente, servir a outros propósitos na seara local, ainda que as tendências inscritas na objetividade presente não apontem nessa direção. 
Ainda sobre os processos cultuais de imposição de determinadas concepções de mundo como legítimas, Bourdieu entende que:

A cultura dominante contribui para a integração real da classe dominante (assegurando uma comunicação imediata entre todos os seus membros e distinguindo-os das outras classes); para a integração fictícia da sociedade no seu conjunto, portanto, à desmobilização (falsa consciência) das classes dominadas; para legitimação da ordem estabelecida por meio do estabelecimento das distinções (hierarquias) e para a legitimação dessas distinções ${ }^{51}$.

O Direito, enquanto produção cultural fortemente influenciada pelas ideias dominantes, por meio das garantias efetiva dos direito individuais, sobretudo os de propriedade, possibilita essa comunicação direta entre as elites do poder, bem como as distingue dos demais estratos da sociedade. Já por meio da constitucionalização dos direitos sociais, porém apenas de maneira programática e em futuro incerto - em que pese a declaração retórica de sua aplicabilidade imediata e direta e do suposto poder de vinculação dos três poderes a esses direitos sociais -, contribui para "integração fictícia da sociedade no seu conjunto", ao auxiliar na construção de uma sociedade aparentemente justa que apenas estabelece diferenciações com base no mérito individual de sujeitos em condições de igualdade.

A nosso ver, o direito é a produção simbólica mais propensa à conservação da ordem como estabelecida, o que é especialmente pernóstico quando as desigualdades sociais são imensas, como no caso brasileiro. Nossa hipótese é que, em razão do desenvolvimento aristocrático, conservador e anti-democrático do campo jurídico nacional, a realidade da descrição de suas funções se aproxima muito mais das descrições marxistas que destacam sua função política de dominação e identificação com a cultura economicamente dominante.

51 BOURDIEU, 1989b, p. 10. 
A ideologia jurídica brasileira está duplamente determinada, não só pelos interesses das elites política e econômica, mas também pelos interesses específicos daqueles que hegemonizam a lógica específica do campo jurídico; as elites jurídicas. $\mathrm{O}$ caráter exageradamente conservador do campo jurídico nacional - crê-se que seja uma característica comum do direito, porém, amplificada pelas características locais - se dá, em partes, pela enorme homogeneidade existente entre os habitus dos indivíduos que compõem as elites do poder no Brasil, o que, por sua vez, favorece a valorização das características compartilhadas por esses agentes. Segundo Bourdieu:

A classe dominante é o lugar de uma luta pela hierarquia dos princípios de hierarquização: as frações dominantes, cujo poder assenta no capital econômico, têm em vista impor a legitimidade de sua dominação quer por meio de sua própria produção simbólica, quer por intermédio de ideólogos conservadores os quais só verdadeiramente servem os interesses dos dominantes por acréscimo, ameaçando sempre desviar sem seu proveito o poder de definição do mundo social que detêm por delegação; a fração dominada tende sempre a colocar o capital específico a que ela deve sua posição, no topo da hierarquia dos princípios de hierarquização. ${ }^{52}$

A partir da leitura do texto transcrito, percebemos que o autor quer diferenciar, dentro das classes dos dominantes (das elites), os interesses e a ideologia específicos das frações dominantes intraelite (dominantes entre os dominantes), assentes no poder econômico, daqueles interesses específicos de seus "ideólogos conservadores", representados por artistas e intelectuais (entre os quais estão os juristas) que lhes servem apenas por acréscimo; é dizer que servem-lhes apenas como consequência da busca de seus interesses particulares.

Bourdieu relata que as frações dominadas entre os dominantes, os ideólogos conservadores, estão sempre

52 BOURDIEU, 1989b, p. 12. 
ameaçando desviar em seu proveito o poder simbólico (pode de definição do social) que lhes é delegado, pois tendem a por o valor a que devem sua posição no topo das hierarquias (no caso dos juristas, o princípio da meritocracia). São essas diferenças que abrem espaços para conflitos entre as diferentes frações que compõe a elite dominante. Porém, essa descrição, que efetivamente dotaria o campo jurídico de um espaço autonomia para a realização da crítica das posições dominantes, depende, em última instância, de uma distinção clara entre as elites jurídica e econômica, entre as frações dominadas e as dominantes.

Num cenário como esse, no qual existe uma distinção mais ou menos rígida entre os dominantes e dominados das elites, a construção dos interesses e objetivos particulares dos juristas poderia opor-se com alguma frequência aos interesses das elites econômica e, eventualmente, impor-lhes limites. Porém, o que acontece quando há uma indiferenciação e/ou forte homogeneidade entre as elites no poder?

\section{Conclusão}

O instrumental metodológico da sociologia relacional, como desenvolvido especialmente por Bourdieu, mas também por muito de seus continuadores e mesmo críticos, representa um recurso fundamental para uma pesquisa sociológica rigorosa sobre o Direito.

As noções de habitus e campo possibilitam superar dialeticamente as abordagens economicistas de inspiração marxista sem recair na filosofia do sujeito racional das teorias da escolha racional, considerando adequadamente o espaço da autonomia do agente e os limites que lhes são impostos pelo ambiente de sua formação e de suas práticas.

No entanto, para que essas ferramentas alcancem o máximo de sua potencialidade, devem ser utilizadas 
não como conceitos estanques, mas como uma espécie de orientação que se molda de acordo com o objeto empiricamente observado. É dizer: não se pode simplesmente "aplicar" os conceitos de campo jurídico e habitus dos agentes jurídicos como desenvolvido alhures à realidade brasileira, na busca de resultados que são moldados por experiências estrangeiras. Ao revés, é necessário se deixar conduzir pela experiência prática, o que demanda o aprofundamento de perspectivas transdisciplinares, visto que não é possível compreender o momento jurídico excluído das demais esferas sociais, notadamente da política e da economia.

\section{Referências}

BAERT, Patrick. Algumas limitações das explicações da escolha racional na ciência política e na sociologia. Revista Brasileira de Ciências Sociais, Tradução de Eduardo Marques, v. 12, n. 35, pp. 1-13, São Paulo, 1997.

BOITOJUNIOR, Armando. Estado, política e classes sociais: ensaios teóricos e históricos. São Paulo: Editora Unesp, 2007. BOURDIEU, Pierre. A distinção: crítica social do julgamento. Tradução de Daniela Kern e Guilherme Teixeira. São Paulo: Edusp; Porto Alegre: Zouk, 2007.

BOURDIEU, Pierre. A gênese dos conceitos de habitus e campo. In: BOURDIEU, Pierre. O poder simbólico. Tradução de Fernando Tomaz. Rio de Janeiro: Bertrand, 1989a.

BOURDIEU, Pierre. As regras da arte: gênese e estrutura do campo literário. Tradução de Maria Lúcia Machado. São Paulo: Companhia das Letras, 1996.

BOURDIEU, Pierre. Capital Simbólico e classes sociais. Tradução de Fernando Pinheiro. Novos Estudos Cebrap, n. 96, pp. 105-115, 2013.

BOURDIEU, Pierre. Meditações pascalianas Tradução de Sérgio Miceli. Rio de Janeiro: Bertrand, 2001. 
BOURDIEU, Pierre. La nobleza de estado: educación de elite y espíritu de cuerpo. Traduzido para o espanhol por Alicia Gutiérrez. Buenos Aires: Siglo Veintiuno, 2013.

BOURDIEU, Pierre. Sobre o poder simbólico. In: BOURDIEU, Pierre. O poder simbólico. Tradução de Fernando Tomaz. Lisboa: Bertrand, 1989b.

BOURDIEU, Pierre; CHARTIER, Roger. O sociólogo e o historiador. Tradução de Guilherme Teixeira. Belo Horizonte: Autêntica, 2015.

BOURDIEU, Pierre. Os usos sociais da ciência: por uma sociologia clínica do campo científico. Tradução de Denise Barbara Catani. São Paulo: Editora UNESP, 2004.

CASTRO, Felipe Araújo. Genealogia histórica do campo jurídico nacional: liberalismo-conservador, autoritarismo e reprodução aristocrática. Tese de Doutorado defendida junto ao Programa de Pós-Graduação em Direito da UFMG, 2018. ENGELMANN, Fabiano. Sociologia do campo jurídico: juristas e usos do direito. Porto Alegre: Sérgio Antônio Fabris, 2006.

FEREJOHN, John; PASQUINO, Pasquale. A teoria da escolha racional na ciência política: conceito de racionalidade em teoria política. Revista Brasileira de Ciências Sociais, v. 16, n. 45, pp. 5-24, São Paulo, 2001.

GOMES, Flávio dos Santos; SCHWARCZ, Lília Moritz. (Orgs.). Dicionário da escravidão e liberdade: 50 textos críticos. São Paulo: Companhia das Letras, 2018.

HORKHEIMER, Max. Teoria tradicional e teoria crítica. In: Max Horkheimer. Os pensadores. São Paulo: Nova Cultural, 1991.

MARCUSE, Herbert. Eros e a civilização: uma interpretação filosófica da obra de Freud. Tradução de Álvaro Cabral. Rio de Janeiro: Zahar, 1975.

MARX, Karl. O18 de Brumário de Luis Bonaparte. Tradução 
de Nélio Schneider. São Paulo: Boitempo, 2011.

PAPILLOUD, Crhistian; SCHULTZE, Eva-Maria. Pierre Bourdieu and relational sociology. In: Fraçois Dépelteau (Org.). The Palgrave Handbook of relational sociology. Springer: Cham, 2018.

POCHMANN, Márcio. O mito da grande classe média: capitalismo e estrutura social. São Paulo: Boitempo, 2014.

POULANTZAS, Nicos. Poder politico y clases sociales em el Estado capitalista. Cidade do México: Siglo XXI Editora, 2007. SOUZA, Jesse. A construção social da subcidadania: por uma sociologia política da periferia. 2 ed. Belo Horizonte: Editora da UFMG, 2012.

TARGA, Leandro Garcez. Os diplomatas brasileiros sob a perspectiva relacional: o campo dos diplomatas e o campo político. Tese de Doutorado apresentada ao Programa de Pós-Graduação em Ciência Política do Centro de Educação e Ciências Humanas da UFScar. São Carlos, 2017.

WACQUANT, Loïc. Poder simbólico e fabricação de grupos. Novos Estudos Cebrap, n. 93, pp. 87-103, 2013.

Recebido em 27/11/2018

Aprovado em 24/04/2019

Felipe Araújo Castro

E-mail: felipeacastro@gmail.com 